\title{
Cerebrovascular carbon dioxide reactivity and failure of autoregulation in preterm infants
}

\author{
Alan C Fenton, Kent L Woods, David H Evans, Malcolm I Levene
}

\begin{abstract}
Changes in cerebral blood flow velocity (CBFV) in response to a rise in arterial carbon dioxide tension $\left(\mathrm{PaCO}_{2}\right)$ in 94 ventilated preterm infants were determined using Doppler ultrasound to assess whether the nature of this change might predict subsequent neurological injury. Concomitant changes in mean arterial pressure (MAP) were recorded. Both CBFV and MAP rose significantly in response to the rise in $\mathrm{PaCO}_{2}$, the response being significantly less in the first 24 hours. Analysis indicated that the change in CBFV in the first day of life in infants $\leq 30$ weeks' gestation was dependent to a great extent on the concomitant change in MAP. Similar dependence also occurred after administration of pancuronium to infants whose CBFV response was previously independent of changes in MAP. This dependency lasted for the duration of paralysis. Changes in CBFV after a rise in $\mathrm{PaCO}_{2}$ did not predict subsequent neurological injury. The influence of pancuronium on cerebrovascular regulation warrants further study.
\end{abstract}

Periventricular leucomalacia (PVL) is an important cause of cerebral palsy especially in sick preterm infants. It results from infarction of the periventricular white matter, ${ }^{1}$ which is a relative vascular watershed. It has been hypothesised that PVL develops if cerebral blood flow is not regulated in the face of changes in blood pressure, ${ }^{2}$ but the exact pathophysiology of its development remains incompletely understood. Little is known about the degree to which preterm infants are capable of regulating cerebral blood flow, or whether the extreme preterm infants who now constitute an increasing proportion of the workload of neonatal intensive care units respond differently to their more mature counterparts.

An important factor mediating cerebral blood flow is arterial carbon dioxide tension $\left(\mathrm{PaCO}_{2}\right)$. The rise in cerebral blood flow in adults, ${ }^{3}$ which accompanies a rise in $\mathrm{PaCO}_{2}$, also occurs in preterm neonates. ${ }^{4}$ However, six of the 19 infants in the latter study had an unexpected response, with cerebral blood flow (assessed with Doppler ultrasound) falling as $\mathrm{PaCO}_{2}$ rose (approximately $1 \mathrm{kPa}$ ). Of these six infants, three subsequently developed PVL, whereas all of the remaining infants, who showed either no change or a rise in cere- bral blood flow velocity (CBFV), had normal cranial ultrasound appearances.

We therefore wished to assess whether the changes in CBFV induced by a rise in $\mathrm{PaCO}_{2}$ might predict subsequent development of $P V L$ in a large group of ventilated preterm infants.

\section{Patients and methods}

The study was performed on the neonatal unit at the Leicester Royal Infirmary. All infants of $\leq 34$ weeks' gestation who were ventilated for idiopathic respiratory distress syndrome (IRDS) were considered eligible. It is our practice for all such infants to have indwelling arterial catheters (either umbilical or peripheral) for blood gas sampling and blood pressure monitoring. Infants were not studied if their condition was considered unstable, if their initial $\mathrm{PaCO}_{2}$ was $>7 \mathrm{kPa}$, if there was no indwelling arterial line, or if there were cranial ultrasound abnormalities at the time of their first study. Infants were studied as soon as possible after birth and daily thereafter until extubation. The study was approved by the Leicestershire district ethics committee and informed parental consent was obtained before enrolling infants in the study.

\section{STUDY PROCEDURE}

Before each study the following measurements were recorded:

\section{Blood pressure}

Blood pressure was measured by a pressure transducer (Spectramed P23XL) attached via non-compliant manometer tubing to the infant's indwelling arterial line as previously described. ${ }^{5}$ A permanent record of blood pressure was made on a chart recorder (Gould) and mean arterial pressure (MAP) noted.

\section{Cerebral blood flow velocity}

In all infants, CBFV recordings were made from one anterior cerebral artery (ACA) using an ATL 600 duplex Doppler system with a $724 \mathrm{~A}$ probe (pulse echo $7.5 \mathrm{MHz}$, Doppler frequency $5 \mathrm{MHz}$ ). The ACA was visualised in the sagittal plane through the anterior fontanelle and signals were recorded from a point midway between the inferior-most border of the corpus callosum and the vessel's origin from the circle of Willis. Care was taken to ensure that the angle of insonation of the vessel was less than $10^{\circ}$.

For these recordings the Doppler sample volume was set to $3 \mathrm{~mm}$ and the high pass wall 
filter at its lowest value $(100 \mathrm{~Hz})$. The ultrasound intensity was kept as low as possible and never allowed to exceed $100 \mathrm{~mW} / \mathrm{cm}^{2}$ SPTA. Doppler signals were recorded onto digital audiotape and subsequently replayed through a fast Fourier transform analyser. ${ }^{6}$ The maximum frequency envelope of 20 or more consecutive beats were extracted and calibrated in terms of velocity using the Doppler equation. The mean velocity over the cardiac cycle was estimated by halving the mean value of the maximum velocity over the cycle. ${ }^{7}$

\section{Ventilatory recordings}

Ventilator settings and whether the infant was paralysed with pancuronium at the time of the study were recorded. Before each study, $0.2 \mathrm{ml}$ of blood was taken from the infant's arterial line for $\mathrm{PaCO}_{2}$ and arterial oxygen tension $\left(\mathrm{PaO}_{2}\right)$ determinations. Routine sedation with an opiate was not used during the course of this study.

\section{Carbon dioxide challenge}

The $\mathrm{PaCO}_{2}$ was then raised (approximately $1 \mathrm{kPa}$ ) by placing a 5-15 $\mathrm{ml}$ deadspace (depending on the weight of the infant) into the ventilator circuit between the ventilator manifold and the end of the endotracheal tube. The deadspace was made of wide bore non-compliant tubing and was shown to be of negligible resistance compared with the endotracheal tube. To confirm that the use of such a deadspace did not affect the ventilator pressures being delivered, airway pressure was measured using a butterfly needle inserted into the endotracheal tube, attached to a pressure transducer (Spectramed P23XL). The $\mathrm{PaCO}_{2}$ was then allowed to equilibrate for 10-15 minutes, the change being monitored where possible by a transcutaneous carbon dioxide electrode. A further $0.2 \mathrm{ml}$ of blood was taken for repeat blood gas analysis, and then repeat MAP and CBFV recordings were made as before.

\section{Real time ultrasound}

Cranial ultrasound appearances were noted daily at the time of each study. After extubation, scans were performed twice each week in the first two weeks after birth and subsequently once each week until discharge. Scans were classified as previously reported ${ }^{8}$; either normal, or showing haemorrhage and/or PVL, the latter being subdivided into prolonged flare or cystic degeneration.

During the study period, 104 infants of suitable gestational age were ventilated for IRDS. Of these, one was excluded because of multiple congenital abnormalities including microcephaly. Three infants died within the first two days of life without being studied, as their condition was judged to be too unstable. CBFV recordings from four infants were unable to be analysed for technical reasons and two infants referred from other hospitals had existing cranial ultrasound abnormalities at the time of referral. The remaining 94 infants were studied on a total of 382 occasions. Their gestational age ranged from 25 to
34 weeks and postnatal age from 2 to 335 hours. Eighty two infants were studied on at least two occasions and the first study was performed at a mean of 15.6 hours after birth.

\section{ANALYSIS}

The results for each day of life were analysed separately using linear regression to examine the factors influencing changes in CBFV for a standardised change in $\mathrm{PaCO}_{2}$ of $1 \mathrm{kPa}$. A step down analysis was used, incorporating MAP, heart rate, and $\mathrm{PaO}_{2}$ as potential explanatory variables. The adequacy of the linear model was checked by plotting residuals. MannWhitney tests were used to compare changes in these variables in infants with and without subsequent cranial ultrasound abnormalities. The effect of gestational age on these changes was also examined. Longitudinal analysis (within subject) was performed using paired $t$ tests to compare changes in CBFV, MAP, and $\mathrm{PaO}_{2}$ with the lower and higher $\mathrm{PaCO}_{2}$ values at different postnatal ages. No adjustment was made for multiple comparisons. The principal findings would not have been altered by this adjustment, which was judged unnecessary because of the small number of comparisons being made. The effects of gestational age was assessed by dividing the infants into two groups: those $\leq 30$ weeks and those $\geq 31$ weeks.

\section{Results}

The following changes were observed in the first week of life.

BASELINE MEASUREMENTS (FIGS 1 AND 2)

Mean baseline CBFV and MAP rose by $46 \%$ $(2 \mathrm{~cm} / \mathrm{s})$ and $11 \%(4 \mathrm{~mm} \mathrm{Hg})$ respectively between the first and second days of life $(\mathrm{p}<0.001, \mathrm{p}=0.01$ respectively). MAP rose by a further $10 \%(4 \mathrm{~mm} \mathrm{Hg})$ over the subsequent 24 hours $(p=0.001)$. Baseline $\mathrm{PaCO}_{2}$ changed little throughout the first week, with somewhat larger day to day variations in $\mathrm{PaO}_{2}$. CBFV was not affected by gestation, but MAP was significantly higher in infants $\geq 31$ weeks compared to those $\leq 30$ weeks $(p=0.01)$ throughout the first week.

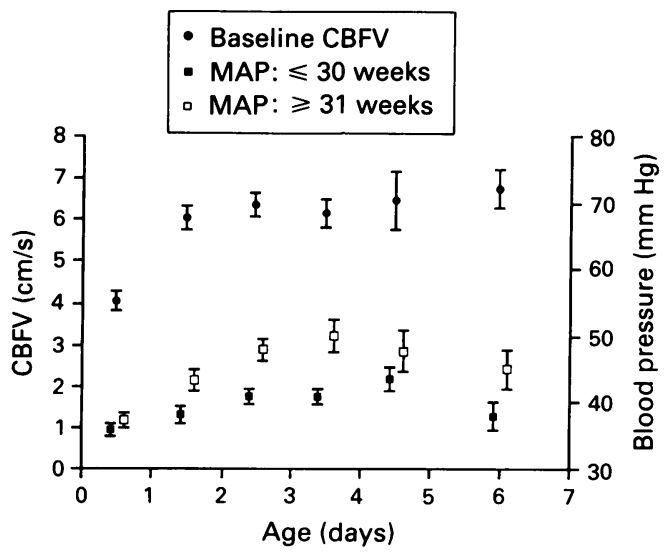

Figure 1 Baseline CBFV and MAP over the first week of life. MAP was significantly higher in infants $\geq 31$ weeks' gestation compared with those $\leq 30$ weeks. Points are mean (SEM). 


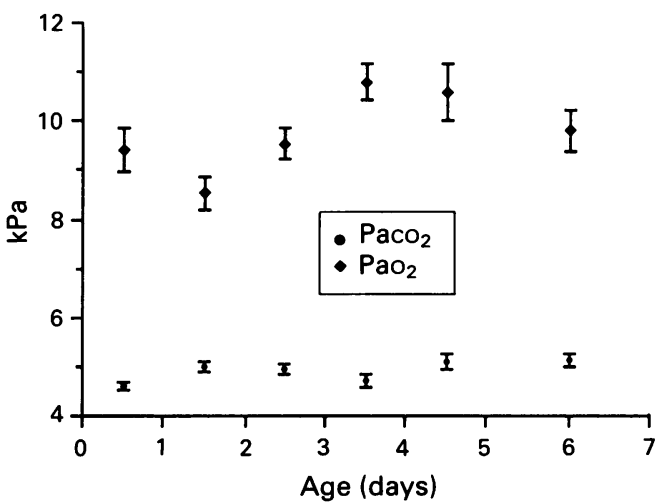

Figure 2 Baseline $\mathrm{PaCO}_{2}$ and $\mathrm{PaO}_{2}$. Points are mean (SEM).

RESPONSE TO INCREASED $\mathrm{PaCO}_{2}$ (TABLE)

The mean induced change in the $\mathrm{PaCO}_{2}$ remained relatively constant from day to day. The mean (SEM) rise in CBFV (for a standardised rise in $\mathrm{PaCO}_{2}$ of $1 \mathrm{kPa}$ ) was $1 \cdot 1(0 \cdot 3)$ $\mathrm{cm} / \mathrm{s}$ during the first 24 hours after birth. This represented a mean increase of $33 \%$ from baseline CBFV ( $p<0.001)$. During the subsequent 24 hours, the mean (SEM) rise in CBFV was $2.1(0.4) \mathrm{cm} / \mathrm{s}$ which was significantly greater $(53 \%, p=0.001)$. Overall, CBFV rose on 322 occasions, fell on 35 occasions (28 infants) and showed no change on 25 occasions ( 21 infants). No infant showed a fall in CBFV on every occasion studied. The CBFV response was not influenced by gestational age.

Overall, the change in MAP was highly significant $(p<0.001)$, rising on 281 occasions, falling on 74 occasions (53 infants), and showing no change on 27 occasions (24 infants). The mean (SEM) rise in MAP was less during the first 24 hours of life $(1.5(0.4) \mathrm{mm} \mathrm{Hg})$ compared with subsequent days $(2.4(0.5)$ $\mathrm{mm} \mathrm{Hg}$ ) but was unaffected by gestation. The contrast between day 1 and day 2 is of doubtful significance in view of the multiple comparisons performed. The fall in MAP was accompanied by a fall in CBFV on 12 occasions in 11 infants, all of whom were $\leq 30$ weeks. On the other occasions when MAP fell, CBFV either remained constant or rose. This occurred in infants of all gestations.

Accompanying significant changes in $\mathrm{PaO}_{2}$ occurred (mean (SEM) rise $1.7(0.6) \mathrm{kPa}$ ) in the first 24 hours $(p=0.006)$, but thereafter were not significant. This response was also unaffected by gestation.

\section{Interrelationship of factors in the carbon dioxide response}

Factors affecting the CBFV response to the rise in $\mathrm{PaCO}_{2}$ varied with both postnatal and

Mean rise in $\mathrm{PaCO}_{2}$ induced and resulting percentage rises in $C B F V$ and $M A P$ (all infants)

\begin{tabular}{lllllll}
\hline \multicolumn{7}{c}{ Age (days) } \\
\cline { 2 - 7 } & 1 & 2 & 3 & 4 & 5 & $6-7$ \\
\hline$\Delta \mathrm{PaCO}_{2}(\mathrm{kPa})$ & $1 \cdot 1$ & $1 \cdot 2$ & $1 \cdot 1$ & $1 \cdot 2$ & $0 \cdot 9$ & $1 \cdot 1$ \\
$\Delta \mathrm{CBFV} / \Delta \mathrm{CO}_{2}(\%)$ & $33 *$ & 53 & 49 & 55 & 52 & 51 \\
$\Delta \mathrm{MAPV} / \Delta \mathrm{CO}_{2}(\%)$ & $5 \cdot 2+7 \cdot 6$ & $7 \cdot 7$ & $8 \cdot 1$ & $8 \cdot 6$ & $8 \cdot 6$ \\
\hline
\end{tabular}

Statistical analysis on days 1 and $2:{ }^{*} \mathrm{p}=0.001 ; \mathrm{pp}=0.04$. gestational age. For infants $\leq 30$ weeks, during the first 24 hours after birth the change in CBFV in response to the rise in $\mathrm{PaCO}_{2}$ depended significantly on the accompanying changes in MAP $(p<0.001$, regression coefficient 0.69 , SD 0.12 ) to which $53 \%$ of the variability (coefficient of determination) in CBFV was attributable (changes in $\mathrm{PaCO}_{2}$ and $\mathrm{PaO}_{2}$ being included in the regression model). This relationship was not significant after the first 24 hours in these infants, or for infants $\geq 31$ weeks both during and after the first 24 hours.

\section{EFFECTS OF PANCURONIUM}

There were 31 infants in the group who received pancuronium to facilitate ventilation after they had been studied on at least one occasion. Of these, 22 had at least two studies while paralysed and at least one further study performed after stopping pancuronium. The decision to use pancuronium was made independently by the clinicians responsible for the infants' care. The gestational ages of the infants on pancuronium were representative of the study group as a whole, as were their baseline values of CBFV, MAP, $\mathrm{PaCO}_{2}$, and the $\mathrm{CBFV}$ and MAP responses to the rise in $\mathrm{PaCO}_{2}$.

Analyses were performed as previously, comparing the infants' response to the rise in $\mathrm{PaCO}_{2}$ before administration to pancuronium (mean postnatal age 10 hours), while paralysed (mean ages 41 and 65 hours) and after stopping paralysis (mean age 119 hours). Before paralysis, changes in CBFV following the rise in $\mathrm{PaCO}_{2}$ were not significantly dependent on MAP, regardless of gestation. After administration of pancuronium changes in CBFV were dependent on MAP $(p=0.015$, regression coefficient 0.84 , SD 0.31 ), with $28 \%$ of the variability in CBFV due to changes in MAP. This dependence persisted for the duration of paralysis $(p=0.014)$, but was not significant after cessation of paralysis. This was independent of gestation.

\section{PREDICTIVE VALUE OF THE CARBON DIOXIDE} RESPONSE

Twenty seven infants $(28 \cdot 7 \%)$ developed mild intraventricular haemorrhage and a further four had severe haemorrhage with parenchymal involvement. Twenty one infants $(22 \%)$ had prolonged flare on cranial ultrasound, of whom nine $(9.6 \%)$ subsequently developed cystic changes. One further infant developed a single small periventricular cyst without preceding flare. The change in CBFV did not predict subsequent development of haemorrhage $(p>0.21)$, prolonged flare $(p>0.33)$ or cystic PVL ( $p>0.36)$, even in gestational age subgroups.

\section{Discussion}

Studies involving the effects of carbon dioxide on the circulation are beset with difficulties, with important ethical and methodological considerations, concerning the degree of $\mathrm{PaCO}_{2}$ manipulation and the way in which this 
is achieved. The method that we have used allowed us to both change the $\mathrm{PaCO}_{2}$ by a significant amount (while remaining within the normally accepted range) and achieve a steady state at the higher level rapidly and consistently, without having to adjust ventilator settings. The latter method would have direct effects on $\mathrm{PaO}_{2}$, which may be detrimental to the infant in addition to potential secondary effects on cardiac function. ${ }^{910}$

A second important consideration is the method used for estimation of cerebral blood flow. Changes in CBFV have been shown to correlate well with actual changes in cerebral blood flow. ${ }^{11}$ In addition, studies examining the relative vasodilatory effects of changes in $\mathrm{PaCO}_{2}$ on cerebral vessels indicate that the smallest pial vessels exhibit the highest degree of dilatation..$^{12}$ In contrast to these surface vessels, intracerebral (parenchymal) vessels show relatively little change ${ }^{14}$ and it may therefore be concluded that most of the cerebral blood flow regulation in response to changes in $\mathrm{PaCO}_{2}$ takes place at the level of these small vessels. Therefore using changes in CBFV in proximal major cerebral vessels as an estimation of changes in actual cerebral flow in response to changes in $\mathrm{PaCO}_{2}$ appears valid.

The characteristics of the infants we have studied are representative of the populations seen in most neonatal intensive care units. Mean baseline values of CBFV and MAP are comparable with published normal ranges. ${ }^{15} 16$ The $46 \%$ rise in baseline CBFV between the first and second days did not appear to be due to the concomitant $11 \%$ rise in baseline blood pressure and subsequent rises in blood pressure were not associated with significant changes in baseline CBFV.

The factors on which the changes in CBFV in response to the rise in $\mathrm{PaCO}_{2}$ depended altered significantly with both gestation and postnatal age. Our data indicate that in the first 24 hours after birth, extremely preterm infants ( $\leq 30$ weeks' gestation) demonstrate changes in cerebral blood flow in response to a rise in $\mathrm{PaCO}_{2}$ which are dependent to a great extent on concomitant changes in blood pressure. They are therefore potentially at greater risk from sustaining ischaemic injury than their more mature counterparts. The mechanisms responsible for this difference remain unclear. The transition to extrauterine life most obviously entails loss of the placental circulation, which in utero tends to damp down circulatory changes due to variations in fetal cardiac output. ${ }^{17}$ After birth, if vasomotor tone is insufficiently mature, changes in blood pressure may directly affect organ blood flow. Reasons for the loss of this pressure passivity in the less mature infants after the first 24 hours are also unclear. However, while neurogenic and humoral mechanisms are thought to play a relatively minor part in the regulation of cerebral blood flow under normal circumstances, ${ }^{18} 19$ under conditions of stress and in the presence of immature vasomotor ton $\mathrm{e}^{20}$ they may have a more influential role. In addition, the catecholamine surge around the time of birth has been shown to influence the behaviour of receptors in lung tissue ${ }^{2122}$ and similar responses may well be induced in other tissues, such as the brain.

Similarly, involvement of neurogenic and humoral factors may be responsible for the changes we have observed after administration of pancuronium. Roizen et al demonstrated that administration of pancuronium resulted in a fall in plasma noradrenaline concentrations in adults, which they felt resulted from a generalised reduction in sympathetic outflow. ${ }^{23}$ There is conflicting evidence in this area, since others have demonstrated both a direct and an indirect sympathomimetic response to the administration of pancuronium. ${ }^{24} 25$ We have recently found that paralysed infants demonstrated pressure passive changes in CBFV at fast ventilator rates, when the $\mathrm{PaCO}_{2}$ was raised using a deadspace. ${ }^{26}$ However, this higher $\mathrm{PaCO}_{2}$ level was not significantly different from that when the infants were ventilated at slow rates, yet at the slower rate CBFV was not blood pressure dependent. It may be that the loss of autoregulation to a $\mathrm{PaCO}_{2}$ challenge which we found in those infants was not a function of fast ventilator rates as we suspected, but rather was related to the use of pancuronium. Our findings of a potential adverse effect of pancuronium in terms of preterm cerebral injury contrasts with previous work $^{27}$ which suggested a beneficial effect in terms of prevention of intraventricular haemorrhage. Clearly caution must be exercised in attaching clinical significance to an unexpected finding on statistical analysis, but we feel the effects of pancuronium in the preterm neonate warrant further study.

While these results are also comparable with our previous study, ${ }^{4}$ they are at variance with those of Pryds et al. ${ }^{28}$ Using an intravenous xenon-133 technique to measure cerebral blood flow, they found a large increase in the change in flow for a standardised rise in $\mathrm{PaCO}_{2}$ between the first and second days of life ( 11.5 and $32.6 \%$ respectively), though again the numbers studied on two occasions were small. These values are lower than others have found using a similar method for assessing cerebral blood flow. ${ }^{29}$ Baseline $\mathrm{PaCO}_{2}$ rose significantly between the first and second days and the absolute change in $\mathrm{PaCO}_{2}$ used $( \pm 0.5 \mathrm{kPa})$ before standardisation to $1 \mathrm{kPa}$ was smaller than in our study, and was achieved by unspecified 'ventilator manipulation'. In view of the potential effects on cardiac output and hence blood pressure that such manoeuvres might engender, it is interesting to note that no specific relation of $\mathrm{PaCO}_{2}$ to blood pressure was noted. Finally, all the infants in that study were paralysed with pancuronium. Clearly the potential effects of pancuronium we have suggested may have influenced their results. In addition, all of the infants in their study received phenobarbitone as part of their management and although conflicting evidence exists, the use of barbiturates may well affect the cerebrovascular carbon dioxide response, mediated by an effect on brain metabolic rate. ${ }^{30}$ 
The failure of our carbon dioxide 'stress' to identity infants who subsequently developed ultrasound evidence of PVL may have been due to several factors. All infants were studied when stable, and thus the carbon dioxide response would have been unaffected by the acute clinical problems to which development of PVL has been shown to be related. ${ }^{31}$ This is unlike the fixed alteration in the carbon dioxide response that occurs in adults with cerebrovascular disease. ${ }^{32}$

In conclusion, we believe there are important implications to our findings that changes in CBFV (which we believe represent changes in cerebral blood flow) after changes in $\mathrm{PaCO}_{2}$ are greatly influenced by accompanying changes in blood pressure both in infants $\leq 30$ weeks' gestation within the first 24 hours after birth and in infants on pancuronium. Since such pressure dependence of flow has been linked to subsequent neurodevelopmental injury, it is clearly important that accurate, continuous monitoring of blood pressure and avoidance of large pressure changes is carried out in these potentially at risk infants.

AC Fenton is supported by the Spastics Society.

1 Banker BQ, Larroche J-C. Periventricular leukomalacia of infancy. Arch Neurol 1962;7:386-410.

2 Pape KE, Wigglesworth JS, Haemorrhage, ischaemia and the perinatal brain. Clin Dev Med 1979;69/70

3 Kety SS, Schmidt CF. The effects of altered arterial tension of carbon dioxide and oxygen on cerebral blood flow and cerebral oxygen consumption of normal young men. f Clin Invest 1948;27:484-92.

4 Levene MI, Shortland D, Gibson N, Evans DH. Carbon dioxide reactivity of the cerebral circulation in extremely premature infants: effects of postnatal age and indomethacin. Pediatr Res 1988;24:175-9.

5 Evans DH, Lark GM, Archer LNJ, Levene MI. The continuous measurement of intra-arterial pressure in the neonate; method and accuracy.Clin Phys Physiol Meas 1986;7:179-84.

6 Schlindwein FS, Smith MJ, Evans DH. Spectral analysis of Doppler signals and computation of the normalised first moment in real time using a digital signal processor. Med Biol Eng Comput 1988;26:228-32.

7 Evans DH, Schlindwein FS, Levene MI. The relationship between time averaged intensity weighted mean velocity between time averaged intensity weighted mean velocity and time averaged maximum velocity in neon

8 Graham M, Levene MI, Trounce JQ Rutter N. Prediction of cerebral palsy in very low birthweight infants: prospecive ultrasound study. Lancet 1987;ii:593-6.

9 Morgan BC, Martin WE, Hornbein TF, Crawford EW, Guntheroth WG. Haemodynamic effects of intermitten positive pressure respiration. Anesthesiology 1966;27: 584-90.

10 Jardin F, Farcot J-C, Boisante L, Curien N, Margairaz A Bourdarias J-P. Influence of positive end-expiratory pres- sure on left ventricular performance. $N$ Engl $f \mathrm{Med}$ 1981;304:387-92.

11 Batton DG, Hellmann J, Hernandez MJ, Maisels MJ Regional cerebral blood flow, cerebral blood velocity and pulsatility index in newborn dogs. Pediatr Res 1983;17: 908-12.

12 Auer LM, Johansson BB. Dilatation of pial arterial vessels. Acto Physiol Scand 1980;109:249-51.

13 Wei EP, Kontos HA, Patterson JL Jr. Dependence of pial arteriolar response to hypercapnia on vessel size. $A m \mathcal{F}$ arteriolar response to hyperca

14 Mchedlishvili G. Blood supply to cerebral tissue. In. Bevan $\mathrm{JA}$, ed. Arterial behaviour and blood circulation in the brain. New York: Plenum, 1986:117-21.

15 Evans DH, Levene MI, Shortland DB, Archer LNJ. Resistance index, blood flow velocity, and resistance area product in the cerebral arteries of very low birth weight infants during the first week of life. Ultrasound Med Biol 1988;14:103-10.

16 Shortland DB, Evans DH, Levene MI. Blood pressure measurements in very low birthweight infants over the first week of life. $\mathcal{F}$ Perinat Med 1988;16:93-7.

17 Nuwayhid B, Brinkman CR III, Su C, Bevan JA, Assali NS. Development of autonomic control of the fetal circulation. Am F Physiol 1975;228:337-44.

18 Wei EP, Ellis EF, Kontos HA. Role of prostoglandins in pial arteriolar response to $\mathrm{CO}_{2}$ and hypoxia. Am $\mathcal{f}$ Physiol pial arteriolar respo

19 Edvinsson L, Mackenzie ET. Amine mechanisms in the cerebral circulation. Pharmocol Rev 1976;28:275-348.

20 Haruda F, Blanc WA. The structure of intracerebral arteries in premature infants and the autoregulation of cerebral blood flow. Ann Neurol 1981;10:303 (abstract).

21 Walters DV, Olver RE. The role of catecholamines in lung liquid absorption at birth. Pediatr Res 1978;12:239-42.

22 Brown MJ, Olver RE, Ramsden CA, Strang LB, Walter DV. Effects of adrenaline and spontaneous labour on the secretion and absorption of lung liquid in the fetal lamb. $f$ Physiol 1983;344:137-52.

23 Roizen MF, Forbes AR, Miller RD, Lake CR, Stanski DR Similarity between the effects of pancuronium and atropine on plasma norepinephrine levels in man. $f$ Pharmacol Exp Ther 1979;211:419-22.

24 Docherty JR, McGrath JC. Sympathomimetic effects of pancur pancuronium bromide on the cardiovasc

25 Domenach JS, Garcia RC, Sasiain JMR, Loyola AO, Oro JS. Pancuronium bromide: an indirect sympathomimetic agent. $B r f$ Anaesth 1976;48: $1143-8$.

26 Fenton AC, Field DI, Woods KI, Evans DH, Levene MI Circulatory effects of fast ventilator rates in preterm Circulatory effects of fast ventilator
infants. Arch Dis Child 1990;65:662-6.

27 Perlman JM, Goodman S, Kreusser KL, Volpe JJ. Reduction in intraventricular haemorrhage by elimination of fluctuating cerebral blood flow velocity in preterm infants with respiratory distress syndrome. $N$ Engl $\mathcal{F}$ Med 1985;312:1353-7.

28 Pryds O, Greisen G, Lou H, Friis-Hansen B. Heterogeneity of cerebral vasoreactivity in preterm infants supported by mechanical ventilation. F Pediatr 1989;115: 638-45.

29 Greisen G, Trojaborg W. Cerebral blood flow, $\mathrm{PaCO}_{2}$ changes and visual evoked potentials in mechanically ventilated preterm infants. Acta Paediatr Scand 1987;76: tilated prete.

30 Fujishima M, Scheinberg P, Busto R, Reinmuth OM. The relation between cerebral oxygen consumption and cererelation between cerebral oxygen consumption and cerebral vascul

31 Calvert SA, Hoskins EM, Fong KW, Forsyth SC Aetiological factors associated with the development of periventricular leucomalacia. Acta Paediatr Scand 1987;76: 254-9.

32 Bullock R, Mendelow AD, Bone I, Patterson J, Macleod $\mathrm{WN}$, Allardice $\mathrm{G}$. Cerebral blood flow and $\mathrm{CO}_{2}$ responsiveness as an indicator of reserve capacity in patients with carotid arterial disease. $\operatorname{Br} \mathcal{F}$ Surg 1985;72:348-51. 